\title{
Observations of Ice Crystals in a Cumulus Cloud Seeded by Vertical-Fall Pyrotechnics
}

\author{
A. I. Weinstein and D. M. Takeuchi \\ Meteorology Research, Inc., Altadena, Calif.
}

(Manuscript received 27 October 1969, in revised form 12 January 1970)

\begin{abstract}
Two vertical-fall silver iodide pyrotechnics were inserted into a supercooled cumulus cloud near Flagstaff, Ariz. Within a few minutes, a turret was observed to extend over $1.35 \mathrm{~km}$ above the cloud top. The temperature within the main body of the cloud below the turret rose by $0.75 \mathrm{C}$.

Formvar replicator film showed that the number of ice crystals in the cloud at the $-5 \mathrm{C}$ level exceeded the number of ice nuclei effective at this temperature by three orders of magnitude.
\end{abstract}

\section{Introduction}

Observations have been reported recently of considerably larger numbers of ice crystals in clouds than there are ice nuclei. The observations have been in both seeded (MacCready and Baughman, 1968) and nonseeded cumuli (Mossop, 1968; Braham, 1964), as well as in natural orographic stratus (Hobbs, 1969; Grant, 1968) and stratocumulus clouds (Koenig, 1968).

This paper presents a similar observation in a seeded cumulus cloud near Flagstaff, Ariz., on 12 August 1965. The seeding agents were two vertical-fall pyrotechnics each of which consumed $25 \mathrm{gm}$ of $\mathrm{AgI}$ while falling $\sim 3 \mathrm{~km}$.

\section{Data}

Fig. 1 shows the visual effects from the seeding. The picture was taken $7 \mathrm{~min}$ after the two vertical-fall pyro-

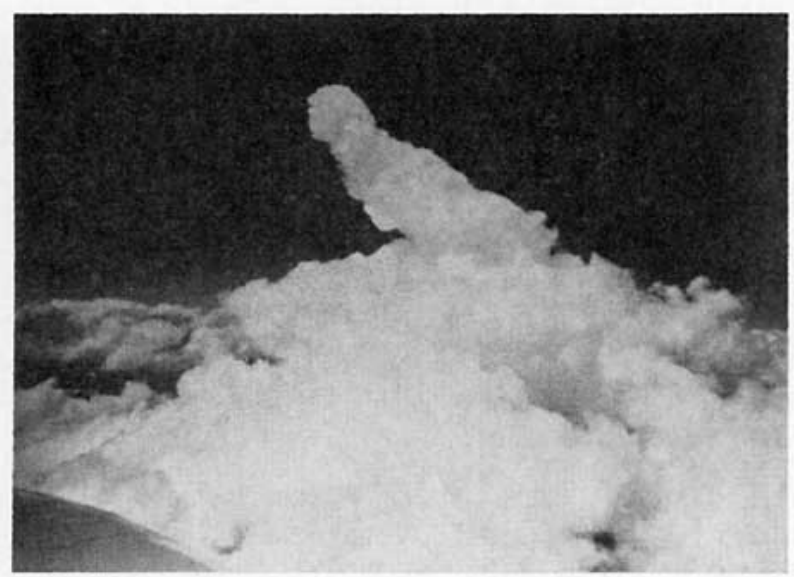

FIG. 1. Dynamic growth effect of seeding by AgI pyrotechnics. Photograph taken near Flagstaff, Ariz., from $6250 \mathrm{~m}$ on 12 August 1965 at 1129 local time, $7 \mathrm{~min}$ after seeding. technics were fired into the top of the cloud. The protuberance initially grew straight up out of the cloud mass, but upper level winds blew the turret into its diagonal position as shown in the figure. The temperatures and altitudes of the tops of the protuberance and main cloud body were $-19 \mathrm{C}$ and $7.6 \mathrm{~km}$ and $-13 \mathrm{C}$ and $6.25 \mathrm{~km}$, respectively. The cloud base temperature and altitude were approximately $5 \mathrm{C}$ and $3.8 \mathrm{~km}$, respectively.

A fully instrumented Twin Comanche made three traverses into the test cloud at $5.8 \mathrm{~km}$. The traverses were made $9 \mathrm{~min}$ before seeding and 5 and $8 \mathrm{~min}$ after seeding. Table 1 shows the values of some of the parameters recorded during the traverses.

An instrumented Twin Beech made a traverse at $5.3 \mathrm{~km}(-5 \mathrm{C})$ at 7 min after seeding. Fig. 2 shows the spatial distribution of ice particles as taken from the MRI Continuous Particle Collector (CPC) film (MacCready and Todd, 1964). Table 2 gives the water droplet observations in the cloud. The $3.3-\mathrm{km}$ cloud showed a $2.0-\mathrm{km}$ region which was substantially glaciated (regions B-D). The cloud edges were almost completely supercooled water. Fig. 3 shows micrographs of representative parts of the CPC film in the supercooled region $\mathrm{A}$ of the cloud, and in the regions that contained ice particles, B-D.

TABLE 1. Observations from instrumented Twin Comanche in test cloud.

\begin{tabular}{|c|c|c|c|c|}
\hline $\begin{array}{l}\text { Time } \\
\text { (minutes } \\
\text { from } \\
\text { seeding) }\end{array}$ & $\begin{array}{c}\text { Tempera- } \\
\text { ture } \\
\left({ }^{\circ} \mathrm{C}\right)\end{array}$ & $\begin{array}{c}\text { Liquid } \\
\text { water } \\
\text { content } \\
\left(\mathrm{gm} \mathrm{m}^{-3}\right)\end{array}$ & $\left(\mathrm{cm}^{\frac{\epsilon^{\frac{1}{3}}}{\sec ^{*}}} \sec ^{-1}\right)$ & $\begin{array}{l}\text { Cloud } \\
\text { diameter } \\
(\mathrm{m})\end{array}$ \\
\hline $\begin{array}{l}-9 \\
+5 \\
+8\end{array}$ & $\begin{array}{l}-8.2 \\
-8.0 \\
-7.5\end{array}$ & $\begin{array}{l}1.5 \\
1.1 \\
0.8\end{array}$ & $\begin{array}{l}0.8 \\
1.0 \\
2.0\end{array}$ & $\begin{array}{l}2000 \\
2600 \\
3320\end{array}$ \\
\hline
\end{tabular}

* Turbulence dissipation coefficient. 


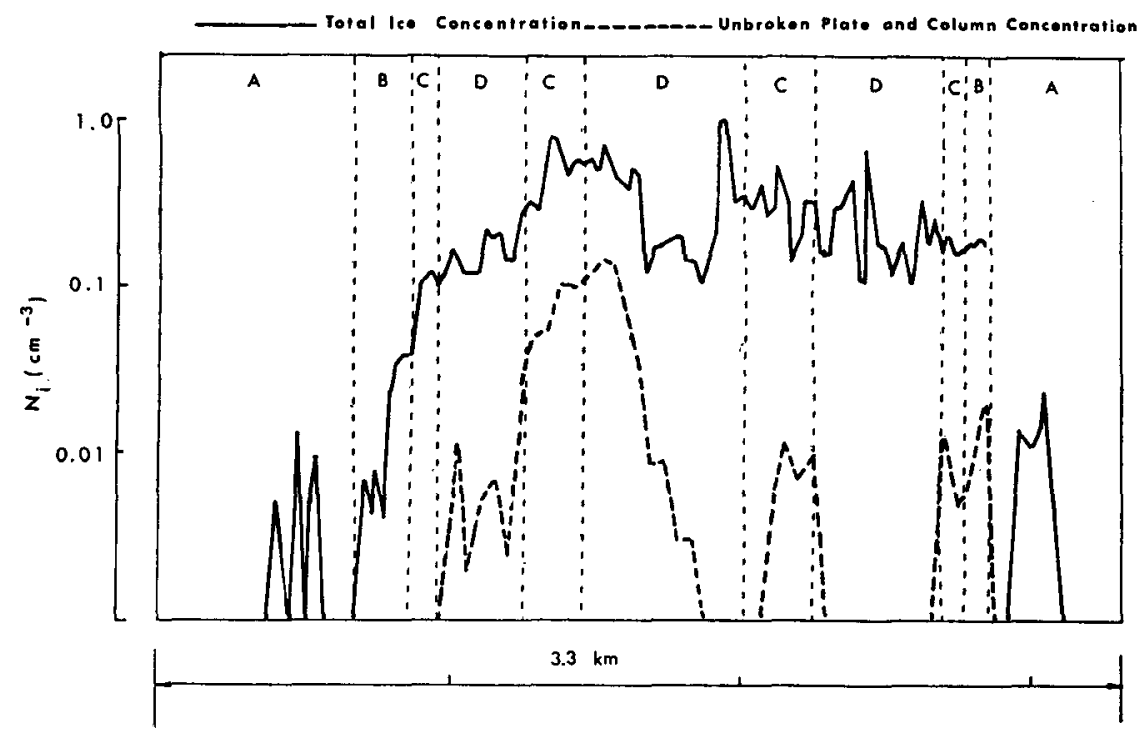

Fig. 2. Spatial distribution of ice particles at $-5 \mathrm{C}, 7 \mathrm{~min}$ after seeding. The solid and dashed curves give the total and unbroken ice particle concentrations, respectively.

\section{Discussion}

The visual effects from the seeding as well as some of the observations from the Twin Comanche can be explained from the conversion of supercooled water to ice. When $1.5 \mathrm{gm} \mathrm{m}^{-3}$ of liquid water are converted to ice, the release of latent heats of fusion and sublimation (MacCready and Skutt, 1967) will liberate enough heat to raise the temperature $0.5 \mathrm{C}$ and $0.15 \mathrm{C}$, respectively. The observed temperature increase in the cloud from $9 \mathrm{~min}$ before seeding to $8 \mathrm{~min}$ after was $0.75 \mathrm{C}$.

A computer model used on a project similar to this one (Weinstein and MacCready, 1969) predicts that the $0.65 \mathrm{C}$ temperature increase would cause the cloud turret to grow from a nonseeded height of $6.04 \mathrm{~km}$ to a seeded height of $7.24 \mathrm{~km}$, i.e., a $1.2-\mathrm{km}$ increase due to seeding. This agrees reasonably well with the $1.35-\mathrm{km}$ depth of the cloud protuberance in Fig. 1.

It should be noted that while two pyrotechnics, horizontally separated by at least $250 \mathrm{~m}$, were fired into the cloud, only one turret rose out of the cloud. Apparently, only one of the pyrotechnics got into the wet core of the cloud. The second one probably hit a relatively dry, inactive part of the cloud. It did not cause enough

TABLE 2. Liquid water observations at $-5 \mathrm{C}, 7$ min after seeding. The regions refer to Fig. 2.

\begin{tabular}{cccc}
\hline Region & $\begin{array}{c}\text { Number } \\
\text { of drops } \\
\left(\mathrm{cm}^{-3}\right)\end{array}$ & $\begin{array}{c}\text { Mean } \\
\text { drop } \\
\text { diameter } \\
(\mu \mathrm{m})\end{array}$ & $\begin{array}{c}\text { Liquid } \\
\text { water } \\
\text { content } \\
\left(\mathrm{gm} \mathrm{m}^{-3}\right)\end{array}$ \\
\hline A & 500 & 16 & 1.00 \\
B & 200 & 13 & 0.24 \\
C & 100 & 13 & 0.12 \\
D & $<25$ & $<10$ & $<0.004$ \\
\hline
\end{tabular}

freezing to occur, to cause enough heat to be liberated, to cause a second turret to grow out of the cloud.

The observations of the dynamic effects of the seeding, while interesting, are not as important as are the ice crystal counts. Looking at Fig. 2, assuming regions $\mathrm{C}$ and $\mathrm{D}$ represent a cylindrical core of $1.9 \mathrm{~km}$ diameter, we get a total ice crystal count of about $10^{10}$ particles per centimeter depth. Each pyrotechnic burned $25 \mathrm{gm}$ of AgI and fell over a depth of $3 \mathrm{~km}$, giving approximately $1.6 \times 10^{-4} \mathrm{gm}$ of $\mathrm{AgI}\left(\mathrm{cm}\right.$ of depth) ${ }^{-1}$ for the two pyrotechnics fired into the cloud. The best estimate available for the number of active ice nuclei per gram of AgI from these pyrotechnics at $-5 \mathrm{C}$ is $10^{11}$ nuclei $\mathrm{gm}^{-1}$ (Finnegan et al., 1967). If anything, this estimate is high. The maximum number of nuclei that could have been produced, then, in the region where the measurements were made, was of the order of $10^{7}$ nuclei $(\mathrm{cm}$ of depth) $)^{-1}$.

The measured number of ice crystals was of the order of $10^{10}$ crystals. It could be said that many of the crystals were the result of a large ice particle shattering on contact with the CPC. We do not believe that this is the case because of the character of the ice crystal replicas on the CPC film. In regions $\mathrm{B}$ and $\mathrm{C}$ in Fig. 2, large, unbroken crystals $(>100 \mu \mathrm{m})$ were found.

In the high concentration and small crystal size (15$40 \mu \mathrm{m}$ ) regions of the traverse, region $\mathrm{D}$ in Fig. 2, the number concentration was very homogeneous within individual frames. If the small crystals were due to shattering of larger ones, there should have been areas of high small-crystal concentrations which would have been the remains of the large crystals. Such remains have been observed in other CPC records.

If the ice crystal counts are taken as real, the ratio of ice crystals at $-5 \mathrm{C}$ to ice nuclei active at $-5 \mathrm{C}$ is 


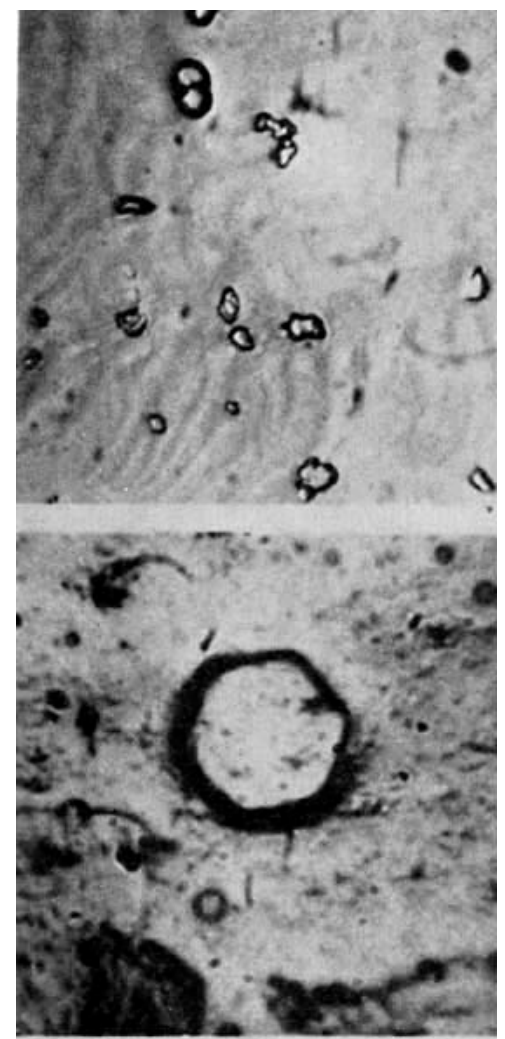

approximately $10^{3}$. This observation is in close agreement with that of Hobbs (1969) at approximately the same temperature in orographic stratus clouds.

The main body of this cloud had a cloud top temperature of $-13 \mathrm{C}$. If the ice crystals were nucleated at this temperature and somehow came down to the $-5 \mathrm{C}$ level, the discrepancy between the numbers of ice crystals and ice nuclei could be explained. This explanation is not considered as likely since it would be hard to explain the small crystal sizes in the $\mathrm{D}$ region of the traverse. Such small crystals would need more than 7 min to fall the distance from the -13 to $-5 \mathrm{C}$ level, particularly with the updraft that had to be present to produce the protuberance shown in Fig. 1.

A second explanation, crystal shattering, has been discussed earlier. It does not appear that crystal shattering could explain the discrepancy.

The third possible explanation is that the generator efficiency value at $-5 \mathrm{C}, 10^{11}$ nuclei $\mathrm{gm}^{-1}$, is off by three orders of magnitude. This possibility cannot be definitely dismissed as the generator calibration procedures commonly used do not simulate the same conditions that exist in cumulus clouds.

Some process of ice multiplication is the final and most widely accepted explanation of a discrepancy of this kind when observed elsewhere.

\section{Summary and conclusions}

An example of a visually dramatic vertical-fall pyrotechnic seeding event has been presented. The dynamic and thermodynamic responses in the cloud were what one would expect from transforming the liquid water into ice.

The number of ice crystals observed in the cloud exceeded the number of ice nuclei that should have been produced at the $-5 \mathrm{C}$ level by three orders of magnitude. This is the first time that a vertical-fall pyrotechnic seeding event has been reported to produce more ice crystals than expected ice nuclei.

Since the production of ice particles in a cloud is the desired result of seeding, it is important to determine how the various ice nuclei generators, in fact, glaciate the cloud. The ice multiplicative process, one possible explanation for the ice crystal/ice nuclei ratio, has strong implications in operational seeding. If this process is effective, then all that an artificial ice nuclei source need do is provide a few ice particles after which the multiplicative process will take over.

Another possible explanation for the ice crystal/ice nuclei ratio, improper ice nuclei generator calibration, also has profound implications in operational seeding. If the ice nuclei generator calibration procedures do not adequately simulate real cloud conditions, their results should not be used to optimize ice phase seeding operations. It is possible that some important nucleation

FIG. 3. Micrographs of typical particles found in the seeded cloud $7 \mathrm{~min}$ after seeding. The top three photographs were taken from regions $B-D$ of Fig. 2, the bottom from region $A$. The largest particle is somewhat greater than $100 \mu$ in diameter. important mechanism in real cumuli but might not be 
simulated in the calibration procedures at all. If one used the calibration procedure results to determine how much material to put into the cloud, the amount introduced could be high by several orders of magnitude. At best, this could only be a waste of seeding material, but at worst, it could lead to drastic overseeding.

Acknowledgments. The authors wish to thank Dr. P. B. MacCready, Jr., of MRI for his suggestion to publish these results and for his help in the overall preparation of the article.

The Twin Comanche aircraft mentioned in the text was supplied by Pennsylvania State University under the guidance of Drs. L. G. Davis and C. L. Hosler under an NSF grant. The Twin Beech was provided by the Desert Research Institute under a contract with the U. S. Bureau of Reclamation.

The work reported here was done under Contracts 14-06-D-5589 and 14-06-D-6581 to MRI from the U. S. Bureau of Reclamation.

\section{REFERENCES}

Braham, R. R., Jr., 1964: What is the role of ice in summer rain showers? J. Atmos. Sci., 21, 640-645.

Finnegan, W. G., L. A. Burkardt and F. K. Odencrantz, 1967: Chemical and physical properties of freezing nuclei from pyrotechnic combustion. Proc. Skywater Conf. No. 1, Physics and Chemistry of Nucleation, Denver, 246-284.

Grant, L. O., 1968: The role of ice nuclei in the formation of precipitation. Proc. Intern. Conf. Cloud Physics., Toronto, 305309.

Hobbs, P. V., 1969 : Ice multiplication in clouds. J. Atmos. Sci, 26, 315-318.

Koenig, R. L., 1968 : Some observations suggesting ice multiplication in the atmosphere. $J$. Atmos. Sci., 25, 460-463.

MacCready, P. B., Jr., and R. G. Baughman, 1968: The glaciation of an AgI seeded cumulus cloud. J.A ppl. Meteor., 6, 132-135.

- , and R. F. Skutt, 1967: Cloud buoyancy increase due to seeding. $J$. Appl. Meleor., 6, 207-210.

- , and C. J. Todd, 1964 : Continuous particle sampler. J. Appl. Meteor., 3, 450-460.

Mossop, S. C., 1968: Comparisons between concentration of ice crystals in cloud and the concentration of ice nuclei. $J$. Rech. A imos., 3, 119-124.

Weinstein, A. I., and P. B. MacCready, Jr., 1969: An isolated cumulus cloud modification project. J. Appl. Meteor., 8, 936947. 